\title{
ESPA from Concept to Flight Hardware
}

\author{
Joseph R Maly Paul S Wilke \\ CSA Engineering, 2565 Leghorn Street, Mountain View, California \\ jmaly@csaengineering.com (650) 210-9000 \\ wilke@csaengineering.com (541) 858-8556 \\ Peter M. Wegner \\ Air Force Research Laboratory, Space Vehicles Directorate \\ 3550 Aberdeen Avenue SE, Kirtland Air Force Base, New Mexico \\ peter.wegner@kirtland.af.mil (505) 853-3486 \\ Lisa Berenberg \\ Aerospace Corporation, US Air Force Space Test Program \\ 3550 Aberdeen Avenue SE, Kirtland Air Force Base, New Mexico \\ lisa.berenberg@kirtland.af.mil (505) 846-8413 \\ Gregory E. Sanford \\ Air Force Research Laboratory, CSA Engineering \\ 1300 Britt Street SE, Suite 201, New Mexico \\ gs@csaengineering.com (505) 853-2422
}

\begin{abstract}
In August of 2003, flight hardware for the EELV Secondary Payload Adapter (ESPA) will be delivered to Cape Canaveral. The ESPA Ring and five spacecraft will launch on an Air Force Delta IV mission scheduled for March 2006. This flight, STP-1, will be the maiden voyage for a payload adapter that was conceived by the Air Force in 1995 to provide a secondary payload capability for Evolved Expendable Launch Vehicles (EELVs). ESPA was designed and flight qualified during the period of 1999 to 2002, for use with both Atlas V and Delta IV launch vehicles. The ESPA Ring provides an American counterpart to the Ariane adapter that has been exploited for European launches since 1990. It is now feasible for up to six secondary spacecraft to be placed in orbit whenever a Delta IV Medium or Atlas V (400 or 500 series) launch is configured with excess payload capacity. Since the majority of EELV launches in the foreseeable future have significant excess capacity, the small satellite community has a significant new option for access to space.
\end{abstract}

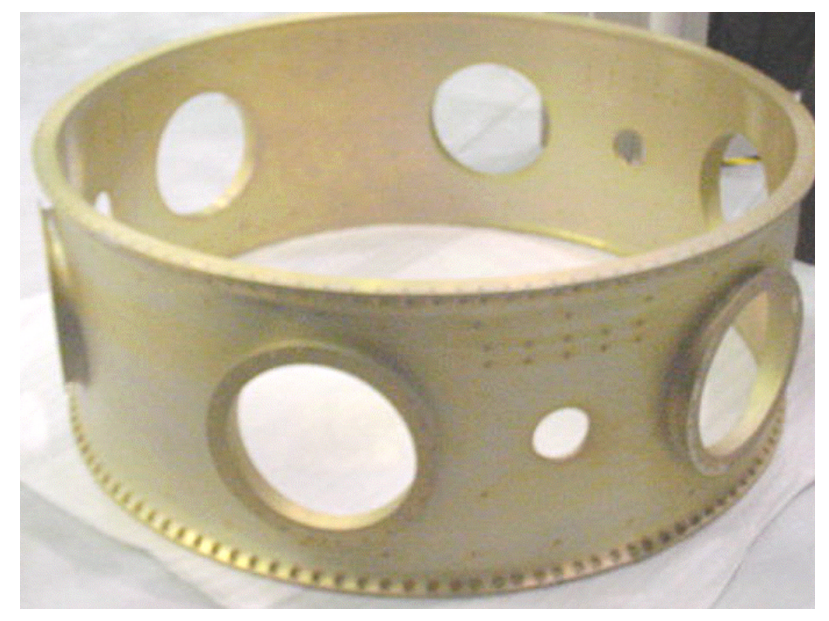

Figure 1. EELV Secondary Payload Adapter 
This paper tells the story of ESPA from conception to the first flight unit. Early discussions on EELV secondary payloads led to formation of a development team by the Air Force Space Test Program (STP). The Air Force Research Laboratory (AFRL) directed the team for STP with contractor support and guidance from Boeing and Lockheed Martin. A design mandate adopted from the beginning demanded no added risk for the primary payload. An early composite/aluminum design was abandoned in favor of a single-piece aluminum structure. Qualification testing at Kirtland Air Force Base added a new capability for STP and the AFRL. "No added risk to the primary" led to including environment mitigation technology such as lowshock separation systems and whole-spacecraft vibration and shock isolation. Integration activities led by the Boeing Company at Cape Canaveral are underway in preparation for the 2006 launch date for STP-1.

\section{Introduction and Overview}

ESPA was conceived as a result of both need and opportunity. In the mid-1990s, the Air Force took the initiative to pursue a secondary payload capability that could be used with the next generation of launch vehicles, in development at the time. This capability targeted an important DoD need at the same time that the EELV program was ramping up to provide the opportunity. Now that the ESPA Ring has been qualified, the Air Force and other government agencies, as well as universities and commercial space entities, will benefit from this new capability for secondary payloads, increasing access to space for small satellites.

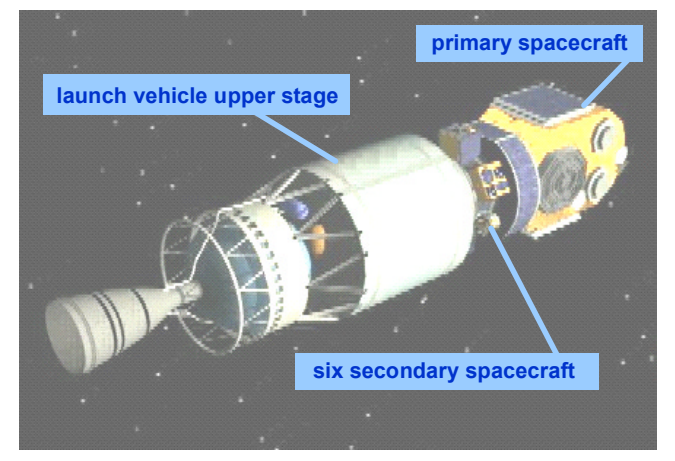

Figure 2. Launch vehicle upper stage with ESPA carrying seven spacecraft to orbit

The Air Force Space Test Program (STP), part of the Air Force Space and Missile Systems Center Detachment 12 (SMC Det 12/ST), recognized early in the EELV Program that the excess capacity that would be available on nearly all EELV launches during the first EELV decade would provide an enormous opportunity to launch small satellites. It was also clear that the increasing number of small satellites seeking launch, by STP and numerous other organizations, required lower cost launch opportunities. Some early studies on the potential savings that could be obtained by merging need and opportunity showed an order of magnitude reduction in cost. It was estimated that launch costs on the order of $\$ 10$ to $\$ 20$ million per spacecraft per launch could be reduced to less than $\$ 1$ to $\$ 2$ million.

To achieve the benefits of anticipated cost savings and increased space access, technical requirements were emphasized from the start of the ESPA program. First and foremost was the overriding requirement that the addition of ESPA and the secondary spacecraft would be nearly transparent to the primary spacecraft.

\section{Thou shalt not provide risk to the primary spacecraft.}

This mandate affected all aspects of the ESPA development. From a structure perspective, it meant the adapter would not alter the system level dynamics, i.e., a primary payload's ride to orbit with ESPA and secondary payloads would not be degraded from what it's launch environment would be as a solo payload. Electrical connectivity needs of the primary could not be compromised. And integration of the primary spacecraft had to be achievable 
without added risk, while adding the complexity of up to six additional spacecraft.

\section{The ESPA Team}

In 1998, STP partnered with the Space Vehicles Directorate of the Air Force Research Laboratory (AFRL/VS) for a joint effort to develop ESPA. Aerospace Corporation was a de facto team member because of their unique support role for Air Force programs. This teaming arrangement provided benefits for both of these Kirtland Air Force Base organizations, beyond the enhanced space access capability that ESPA would provide. For example, environment mitigation technologies under development at AFRL for ESPA spacecraft are targeting benefits for STP planned payloads. And the structural qualification test facility that was built for ESPA at AFRL has expanded the capability available to STP beyond the existing Aeronautical Engineering Facility (AEF) at Kirtland, where extensive environmental testing has been performed for years.

Also in 1998, CSA Engineering was awarded an Air Force SBIR (Small Business Innovative Research) contract for the design of a payload adapter that could be used on EELV (Atlas V and Delta IV) to integrate the functions of secondary spacecraft attachment and whole-spacecraft vibration isolation. CSA joined the existing STP/AFRL/ Aerospace Corp team, bringing a focus on system level structural dynamics, and performed the mechanical design, structural and dynamics analyses, and the qualification testing of the ESPA. Now that the Ring is designed and qualified, and EELV flight data is becoming available, isolation systems are under development.

Northrop Grumman (TRW at the time) played a key role on the ESPA team. Based on extensive experience with aerospace systems, TRW engineers provided system level support throughout the evolution of the ESPA Ring, and preliminary designs for an ESPA electrical harness. During the final two years of the development effort, Steve Buckley of TRW was an invaluable team asset as senior technical adviser for the AFRL.

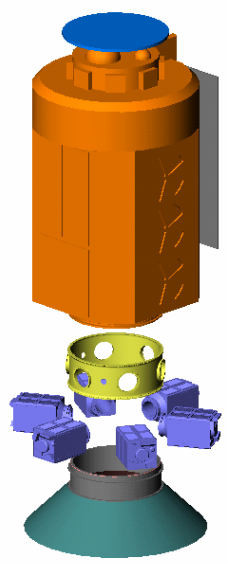

Figure 3. ESPA with primary spacecraft and six secondary spacecraft

Development of the ESPA required detailed knowledge of the launch vehicles, and both EELV manufacturers contributed throughout the ESPA development and testing, as subcontractors to the ESPA team. Boeing and Lockheed Martin provided structural models and loads, as well as valuable technical guidance and support. Special Studies performed by both contractors provided extensive technical details. Planner's guides for both Atlas V and Delta IV were referenced extensively during the ESPA development phase. Qualification testing was performed with a test program derived from Atlas $\mathrm{V}$ and Delta IV requirements. During test program development, a general-purpose static test facility was designed and built for the Air Force Research Laboratory at Kirtland Air Force Base.

Hardware components for environment mitigation, including low-shock separation systems, are evolving, as the dynamics environments for both vehicles are being defined and documented. Vibration and shock isolation systems for reducing the launch 
environment seen by the payloads are optional components of the ESPA system. Low-shock separation systems and shock isolation hardware have been built and tested. Vibration isolation systems are under development.

Finally, integration support for the STP-1 mission is ongoing, with the inevitable issues involved with bringing together numerous technical communities for the common goal of a future launch. Boeing has been selected as the Integration Contractor for STP-1, the March 2006 Delta IV Mission that will debut ESPA, the EELV Secondary Payload Adapter.

\section{$\underline{\text { ESPA Origins }}$}

In November of 1995, STP attended the first EELV Payload Integration Working Group (PIWG). Les Doggrell of Aerospace Corp inquired about secondary payload capability for this new generation of launch vehicles. At that time, the EELV System Program Office (SPO) had no plans to support secondary payloads. It should be noted that the SPO was leading an enormous development program involving four independent contractors vying for downselect, and a primary payload capability had to precede a secondary capability. Nevertheless, after this meeting, interest in putting an adapter for secondary payloads on EELV was sparked and numerous discussions ensued.

At an EELV PIWG in April 1996, Capt Dave Tobin of STP presented a vision of EELV secondary payloads that would enable STP to achieve objectives for launching small satellites. The need for more launch capacity was pushing its way into the opportunity presented by EELVs. Capt Tobin described a situation where most of STP's Space Experiments Review Board (SERB) experiments were never launched because of lack of funding. Many STP payloads were microsat-compatible, and there were microsats on the market that could put two or three experiments on a small spacecraft. But the satellite costs would be dwarfed by the cost of the launch, thus requiring tough down-select decisions and keeping valuable payloads grounded. The Ariane Structure for Auxiliary Payloads (ASAP) was being launched about once a year, providing low-cost access to space for small spacecraft, but US policy forbids use of foreign launch vehicles for Government payloads. With EELV requirements being written, it was obvious to STP that the Air Force Space Command (AFSPC) should specify a secondary payload capability for EELV.

Interest in the concept continued to grow. Capt Gary Haag of STP became familiar with Ariane's ASAP secondary ring while researching the capabilities of Surrey satellites for STP missions. Capt Haag sketched an ASAP-like concept the night before an SMC meeting with the SPO and potential EELV contractors. This concept was similar to the ASAP Ring with a mounting shelf for multiple microsats, but it also had some potential enhancements to the ASAP approach: a propulsion module within the structural Ring for transfer to geostationary orbit and an option to instrument the Ring so it could act as a spacecraft bus. Capt Haag also recognized what was to become the ESPA design mandate: "Thou shalt not provide risk to the primary spacecraft." The reception from the SPO was lukewarm and the briefing was uneventful, but industry engineers approached Capt Haag for his drawings and seemed to embrace the idea despite the industry stance that there was no sustainable market for a secondary capability. (This position was not unexpected--launch vehicle manufacturers target sales of launch vehicles.)

Both the SPO and the EELV contractors had no interest in addressing EELV secondary payload capability. STP lobbied AFSPC to write a formal SPO requirement, but Space Command and the SPO argued that a requirement for secondaries was implied 
within the existing requirement set. In 1997 , Lt General DeKok, Commander of the SMC, stated that secondary payloads could be flown on EELVs, but the secondaries must bring their own adapter and be part of the payload.

During this time, the cantilever secondary mount used in the final ESPA design was being debated compared to the ASAP "shelf" configuration. The cantilever mount required addressing issues such as separation system design, isolation system design, and spacecraft handling, but it would allow secondary spacecraft to release prior to the primary spacecraft being separated. (Release of SPLs prior to PPL release does, indeed, violate the no-risk-to-PPL mandate, but this capability retains significant mission-specific options.)

STP initiated discussions with Gene Fosness of the Space Vehicles Directorate of the Air Force Research Laboratory (AFRL). It was clear that development of an adapter such as ESPA would require assembling a capable development team. STP would provide the requirements and direction. AFRL targeted the technical aspects of ESPA development, emphasizing existing strengths in launch vehicle and spacecraft environment mitigation. Aerospace Corporation, in its role as engineering support for the Air Force, was on board for technical support.

In March of 1998, Capt Bruce Wilder briefed the EELV Auxiliary Payloads Workshop. Capt Wilder presented the sketch shown in Figure 4, which is similar to the eventual ESPA design. The momentum for ESPA was gathering, and STP continued to promote an EELV Operational Requirements Document
(ORD) requirement that rockets carry secondary payloads. The requirement was not established, however, because Space Command did not have an operational requirement for small satellites, and research and development spacecraft were not separately addressed in the ORD. Capt Wilder also presented anticipated cost benefits, which are close to current savings estimates. Also in March 1998, a Memorandum of Agreement was established with the Air Force Research Laboratory for a \$2 million joint development effort. CSA Engineering was awarded an SBIR contract from AFRL to develop a payload adapter for both EELVs to integrate the functions of secondary spacecraft attachment and wholespacecraft vibration isolation. TRW then joined the ESPA team to provide system level guidance and support on electrical interface requirements.

By mid-1998, Capt Scott Haskett took over at STP for the ESPA Program. Capt Haskett brought a focus to the program that he communicated to the EELV contractors and eventual ESPA community. He presented the ESPA concept in a wideranging series of briefings across the country. By this time, Capt Haskett, as the STP Program Manager, was in a position to state that ESPA was funded and under development. He presented a plan, and wasn't asking for funding. STP had assembled a team to develop an EELV secondary payload adapter, and the momentum was established that would lead to the flight qualified ESPA Ring by the summer of 2002 .

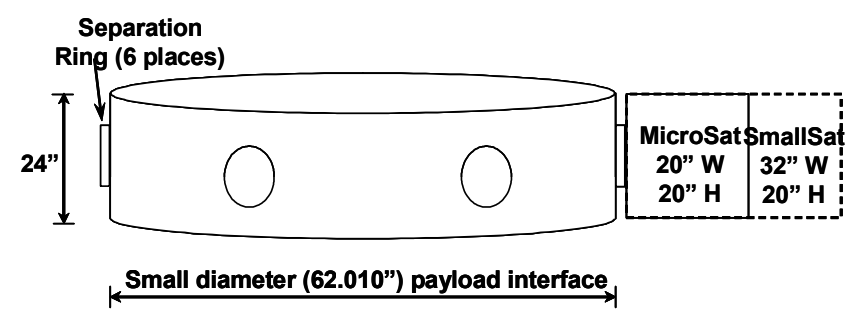

Figure 4. 1997 ESPA concept 


\section{ESPA Structure Design}

The design philosophy behind ESPA from its inception was to be as transparent as possible to the primary payload (PPL). ("Thou shalt not provide risk to the primary spacecraft.") The goal of adding six secondary payloads (SPLs) with minimal impact on the PPL had numerous aspects, including electrical, thermal, and integration issues. With regard to structural design, the approach taken was to make the ESPA structure itself as stiff as possible and to provide optional vibration or shock isolation. This design philosophy meant that system level structural dynamics had to be considered from the beginning, in addition to requirements for strength and functionality.

From the beginning of the design effort, ESPA targeted maximum utilization of EELV capability, i.e., PPLs up to $15,000 \mathrm{lbs}$ with center of gravity (CG) 120 inches above the Standard Interface Plane (bottom of ESPA), and six 400-lb SPLs, with CGs up to 20 inches from the ESPA secondary flanges. Strength requirements were obtained from the Delta IV Payload Planner's Guide and the Atlas V Mission Planner's Guide. Worst-case load factors from these documents were combined to provide PPL load factors for ESPA design. SPL load factors for design were conservatively set at $10 \mathrm{~g}$ axial/10 $\mathrm{g}$ lateral applied simultaneously. The interface configuration for the PPL bolt circles was based on requirements from the EELV Standard Interface Specification. SPL mounting was chosen to be a 15 -inch-diameter bolt circle.

\section{Composite ESPA Design}

In order to meet the design objective of structural "transparency" to the primary payload, graphite/epoxy composite was the design material of choice because of its high stiffness-to-weight ratio. The preliminary design consisted of a 0.3 -inch-thick composite cylinder, with aluminum flanges top and bottom, and aluminum mounting rings for the SPLs. Composite ESPA models were built and analyzed, and the preliminary design was optimized. An internal ring stiffener, at the equator of the main cylinder was included to provide lateral stiffness for the SPLs. This stiffener ring was envisioned to double as an equipment shelf. Detail design of the aluminum composite joint was performed prior to the preliminary Design Review.

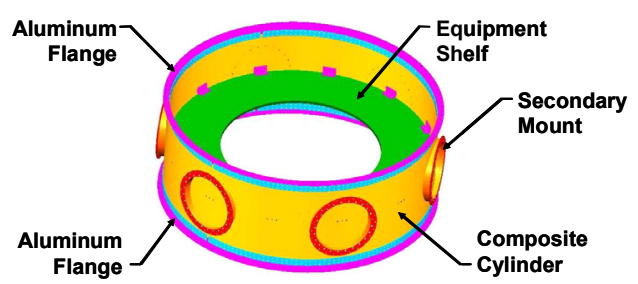

Figure 5. Composite ESPA configuration

The composite design was presented at a Preliminary Design Review attended by representatives of the EELV community, and it was well received from the perspective of mechanical design. However, during a design review for the ESPA Qualification Test, a launch vehicle engineer remarked that studies on ESPA-like adapters compared allaluminum structures to composite and composite/aluminum structures, and the studies favored all-aluminum construction. Besides being easier to manufacture, acceptance testing would not be required on each unit after initial qualification testing. The ESPA design team discussed this issue at length, and decided to initiate a trade study to determine the impacts on stiffness, weight, and strength if the design were to be changed to all-aluminum construction.

\section{Aluminum ESPA Trade Studies}

The trade study on aluminum versus composite began by considering several payload configurations with fixed base boundary conditions for comparison with the composite design. The material properties for the main cylinder in the structure finite element model were changed to (isotropic) aluminum. An aluminum cylinder with wall 
thickness of 0.4 inches resulted in key modal frequencies that were very close to those for the 0.3-inch-thick composite design. The primary payload rocking modes decreased slightly for the aluminum, but the lateral rocking modes of the secondary payloads all increased in frequency. A more detailed study was then begun, to look at various design parameters, such as stiffeners, wall thicknesses, and aluminum material types.

In the finite element model, the parameters were configured so that vertical and horizontal stiffeners could be added or removed for various wall thicknesses. The trade study looked at cylinder wall thickness ranging between 0.15 inches to 0.5 inches. Machined stiffeners, integral to the aluminum cylinder, were included for various cylinder wall thicknesses. Figures of merit for the various designs were axial stiffness of the overall cylinder, and "secondary tangential" stiffness, which was the stiffness computed with a lateral load (tangential to the ESPA cylinder) applied to the center of gravity of the secondary payload. The stiffness of the composite ESPA was compared with the various aluminum configurations.

One all-aluminum design that exceeded the axial stiffness of the composite design was a configuration with 0.5 -inch-thick wall and no stiffeners. This configuration had more than double the lateral stiffness of the composite design without requiring an internal stiffening ring. Even though the weight of this configuration was nearly $100 \mathrm{lbs}$ greater than the preliminary composite design, it was decided that the 0.5 -inch-wall configuration was preferable to more complex aluminum designs with stiffeners. This decision was based on the simplicity of manufacturing the entire ESPA from a single forging of aluminum, without overly complex machining. ${ }^{1}$

\footnotetext{
${ }^{1}$ When the design load factors were finally established for the SPLs (after the ESPA Critical Design Review),
}

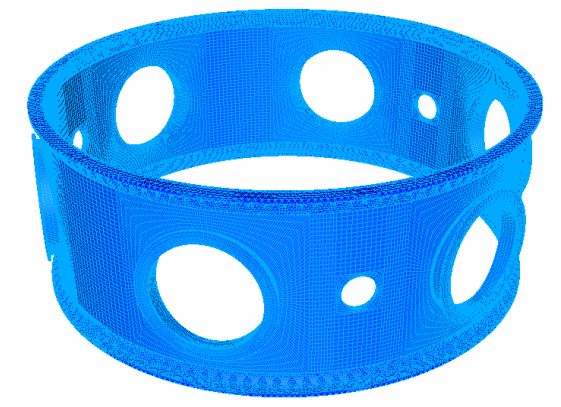

Figure 6. ESPA finite element model

Based on positive feedback from machine shops and the results of the preliminary stiffness trades, complete finite element and solid models were built of the aluminum ESPA (with 0.5-inch-wall thickness and no stiffeners), and a final design trade study was performed. This analysis compared the 0.5inch-wall aluminum ESPA, with and without openings behind the secondary mount rings, to the 0.3-inch-wall composite/aluminum ESPA. Openings within the secondary mount rings were considered desirable for secondary payload access and clearance, so, for this study, the entire area interior to the rings was removed, for a worst-case comparison. The results of this study indicated that the allaluminum ESPA with 0.5-inch wall thickness is stiffer for all payload configurations studied than the preliminary composite design.

By late summer of 2000, a final decision was made to proceed with the all-aluminum ESPA with 0.5 -inch-thick wall. This decision was based on consideration of all impacts of the design change, above and beyond the structural aspects, including cost, schedule and system level issues.

this high tangential stiffness would prove to be an important design driver. Subsequent design studies of a composite ESPA with the final design load factors for the SPLs showed that there would be no weight benefit for a composite design compared to the aluminum ESPA as built. 


\section{Primary Flange Design}

With confidence achieved in an aluminum configuration, a design for the primary interface bolt flanges was developed. Keeping the ESPA design mandate in mind (for mechanical design, transparency to the primary payload meant no degradation to launch stack stiffness), it was imperative that minimal compliance was added at this crucial interface. Furthermore, in cases where primary payload vibration isolation would be beneficial, compliance at this interface must be carefully designed.

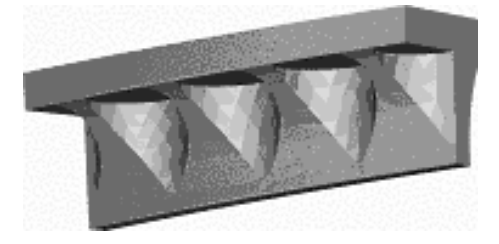

Figure 7. ESPA flange detail

A flange configuration was devised to include the following features:

- an exterior gusset from the outer flange diameter to the cylinder wall, for added stiffness and ease of machining,

- an inner gusset to accommodate a more direct load path between ESPA and mating structure, and

- reverse counterbores used to spotface bolt locations on the outer diameter.

A detailed finite element model of this flange configuration was built (Figure 7), and stiffnesses were computed and used to size an equivalent model of the flange with shell elements. This primary flange design was incorporated in the final design.

\section{System Analyses with Launch Vehicle Models}

Once a design was finalized, system analysis runs were performed to understand the launchstack impact of ESPA on the PPL and SPLs. Maximum-design-weight payloads, i.e., 15,000-lb PPL and 400-lb SPLs, were used for these analyses. Load cases from Atlas V and
Delta IV were analyzed. Each load case was executed for

- the baseline case of the primary payload only (no ESPA),

- the "fully-loaded" ESPA (with PPL and six SPLs), and

- the case of fully loaded ESPA with shock isolation for all payloads.

For all three load cases, the addition of ESPA and six SPLs, or the addition of ESPA with shock isolation for all payloads, had minimal effect on the responses that were monitored. While this analysis sequence was not intended to be a complete study of this subject, it provided a very positive indication that the ESPA design achieved the goal of structural transparency to the primary payload.

An analysis was then performed to demonstrate the effect of ESPA on the primary payload mode frequencies. The important fundamental modes of the primary payload are the first two rocking modes and the bounce mode. Table 1 shows the frequencies at which these modes occur for the 15,000-lb design PPL, with fixed-base boundary condition, as well as on the launch vehicle with and without ESPA. The first rocking mode drops from $14.8 \mathrm{~Hz}$, fixed base, to $5.9 \mathrm{~Hz}$ on the launch vehicle. When ESPA is included in the launch stack, the frequency is further reduced to $5.4 \mathrm{~Hz}$. Similarly the $14.8-\mathrm{Hz}$ second rocking mode (fixed base) drops to $6.2 \mathrm{~Hz}$ on the launch vehicle, and this mode is at $5.5 \mathrm{~Hz}$ when ESPA is included. The bounce mode of the primary payload drops from $32.1 \mathrm{~Hz}$ (fixed base) to $16.9 \mathrm{~Hz}$ on the launch vehicle; this mode is at $16.3 \mathrm{~Hz}$ when ESPA is included in the stack. It should be noted that the EELV requirement of $8 \mathrm{~Hz}$ minimum frequency is for a fixed-base payload stack including adapters. The addition of ESPA would result in violation of this requirement only for marginal cases where the PPL alone would be close to violating this minimum frequency. 
Table 1. Stack mode frequencies with and without ESPA

\begin{tabular}{|c|c|c|c|}
\cline { 3 - 4 } \multicolumn{2}{c|}{} & \multicolumn{2}{c|}{$\begin{array}{c}\text { On launch vehicle } \\
\text { w/ ESPA }\end{array}$} \\
\cline { 2 - 3 } & Fixed base & On launch vehicle & 5.4 \\
Rocking & 14.8 & 5.9 & 5.5 \\
Rocking 2 & 14.8 & 6.2 & 16.3 \\
Bounce & 32.1 & 16.9 & \\
\hline
\end{tabular}

\section{Trade Study on Allowable Secondary Spacecraft Mass Properties}

Since the ESPA design was driven by stiffness requirements, high strength margins were obtained for the design payloads. Strength analysis showed that peak stresses always occurred in the vicinity of the SPL flanges, largely due to the conservative SPL load factors applied simultaneously in two directions. These high strength margins led to the inevitable question from potential SPL users of ESPA: "How much can we push the design envelope for SPLs, i.e., $400 \mathrm{lbs}$ at 20 inches?"

A study was performed to provide data for payload planners regarding how payloads at various weights and center-of-gravity locations (with respect to ESPA's secondary payload flanges) will affect the maximum stress in ESPA. A set of isoclines was generated on a plot with payload weight on the abscissa and center-of-gravity (CG) location on the ordinate.

ESPA factors of safety were calculated using the strength analysis model. The maximum primary-payload lateral (limit) load and corresponding axial (limit) load were applied at the primary payload center-of-gravity location (120 inches from the base of ESPA); the lateral load was $37,500 \mathrm{lb}$ and the axial load was $52,500 \mathrm{lb}$. Secondary payloads with weights of $300,350,400$, and $450 \mathrm{lb}$ were used, and $10 \mathrm{~g}$ limit loads were applied at CG locations of 15, 20, 25, and 30 inches outboard of the secondary payload flanges; each weight was calculated at all four CG locations. From these sixteen sets of data, any other factor of safety (or stress) from a CG-weight pair lying within the data set could be determined, and the isoclines were generated from these results. Figure 8 shows isoclines of constant factors of safety for von Mises stress in ESPA.

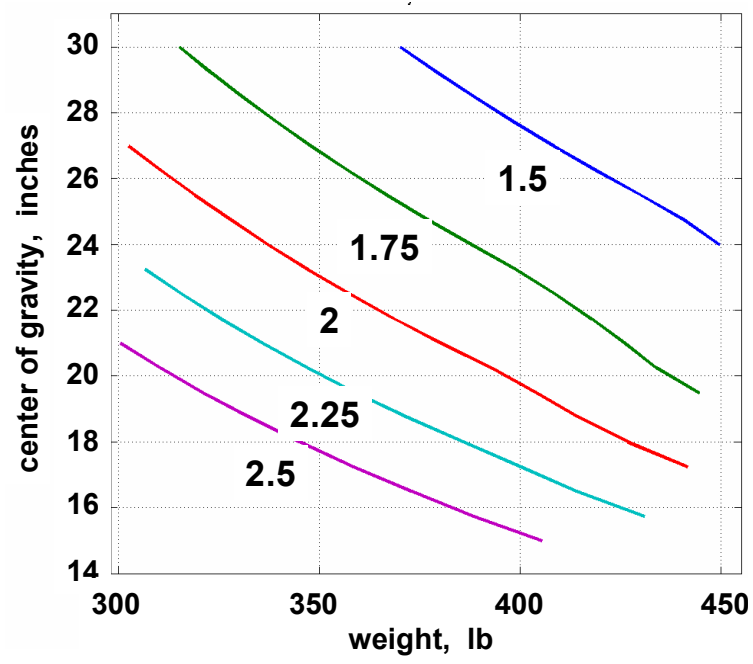

Figure 8. ESPA yield strength factor of safety isoclines, based on weight and center-of-gravity location of secondary spacecraft 


\section{Strength Analysis and Qualification Testing}

Qualification testing of ESPA consisted of subjecting the structure to static loads representing the Maximum Predicted Environment (MPE), with a qualification factor of 1.25. The MPE was determined by enveloping load factors for Delta IV and Atlas $\mathrm{V}$ for the primary payload, and by conservatively selecting load factors for the secondaries with concurrence by both Lockheed Martin and Boeing.

Testing was performed with a test facility developed as part of the ESPA program with support from both Boeing and Lockheed Martin. CSA designed and built the reaction frame, shown in Figure 9, and designed and performed the qualification test. The generalpurpose static test frame at AFRL expanded the test capability available to STP for qualification test programs.

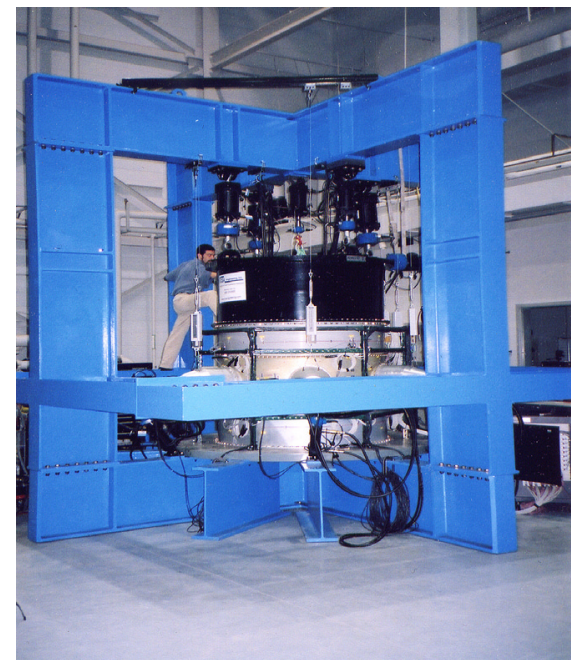

Figure 9. Static test facility at AFRL developed under ESPA program

Strength analyses were performed at several stages during the development of ESPA, including during the initial aluminum structure design and during the design of the qualification test and test structure. Finite element predictions of stress fields and maximum stress levels were consistent throughout these analysis sequences. The analysis performed during the qualification testing of ESPA used a finite element model that was correlated with measured stiffness load cases. This strength analysis used the qualification load cases and load levels that were finalized based on the Test Readiness Review held at Kirtland Air Force Base in January 2002.

Figure 10 shows the finite element model that was used for the strength analysis. This is the model of the qualification test stack, and includes the PPL and SPL load heads as well as the aluminum test adapters on the fore and aft ends of ESPA.

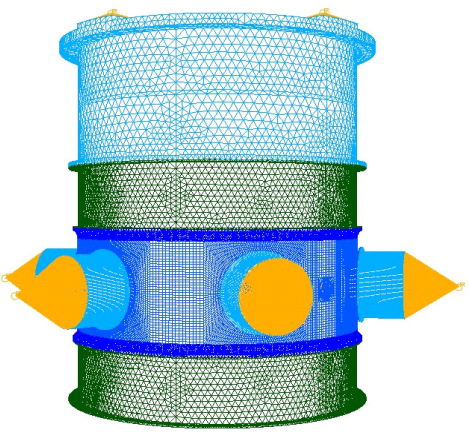

Figure 10. Finite element model of ESPA test stack for stress analysis

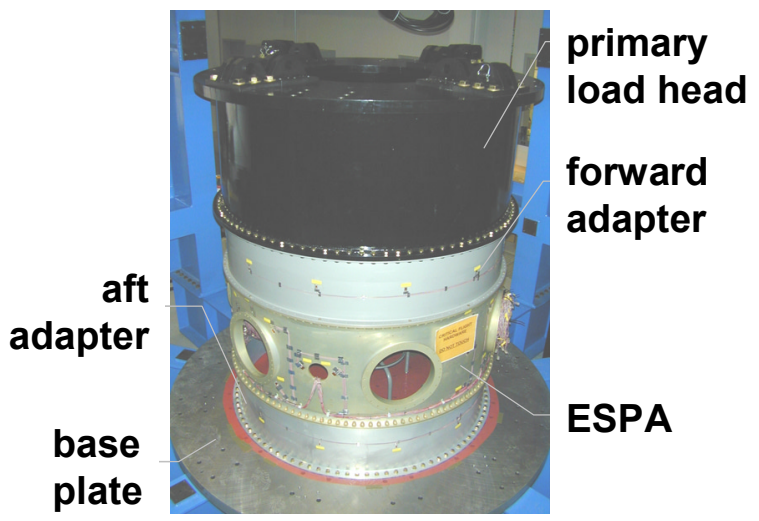

Figure 11. ESPA test stack hardware

Figure 11 and Figure 12 show the test stack hardware. The test adapters were designed to provide realistic interface stiffnesses at the ESPA primary bolt interfaces, as were the SPL load heads for the secondary bolt interfaces, which provided an appropriate configuration for the final strength analysis. 


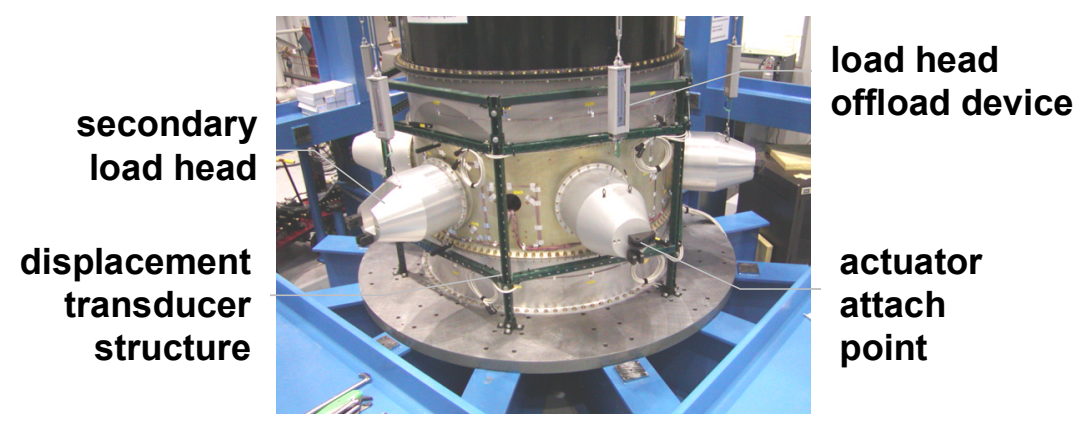

Figure 12. ESPA test stack with secondary load heads

The structural qualification load factors on the primary payload were based on worst-case flight conditions, as published by the EELV manufacturers in the launch vehicle payload planner's guides. Limit load factors on the secondary payloads were conservatively estimated to be $10 \mathrm{~g}$, applied simultaneously in lateral and axial directions, in the same direction as the PPL loads. ${ }^{2}$ Three combinations of axial and lateral loads were found to represent these load profiles. Because the ESPA structure is axially symmetric about the launch vehicle thrust vector, the direction of the lateral load creates unique load profiles in the structure. These various load profiles were fully encompassed by applying the combination of axial and lateral loads in two configurations for a total of six load cases. The first configuration consisted of the axial loads being applied simultaneously with the lateral loads in the $+Y$ direction. The second configuration had the same axial loads and the lateral loads applied in the $+\mathrm{Z}$ direction. The coordinate systems used throughout the design, analysis, and testing of ESPA are presented in Figure 13.

The primary loads were calculated from a combination of a 15,000-lb payload, with

\footnotetext{
${ }^{2}$ Load factors for the SPLs were taken to be the same as the PPL load factors until the ESPA Critical Design Review in January 2001. At this time Boeing and Lockheed Martin both provided input that higher load factors are required for secondary payloads. By March of 2001, a consensus was established that $10 \mathrm{~g}$ applied simultaneously in two directions would be adequate, albeit conservative.
}

center of gravity 120 inches from the aft end of ESPA, and the mass of a flight ESPA (estimated at $350 \mathrm{lb}$ ) with a center of gravity 12 inches from the aft end of ESPA. All primary loads were assumed to be in the primary payload coordinate system. Loads for secondary payloads were calculated based on 400-lb SPLs, with each load applied at the individual SPL center of gravity

Qualification loads applied to the finite element model for the strength analysis represented the Maximum Predicted Environment (MPE) times the qualification factor of 1.25. Standard gravity loading could not be used due to the two different sets of load factors, so point loads were applied at the payload centers of gravity. The yield factors of safety $^{3}$ for ESPA with these worst-case loads are all around 2.0; the ultimate safety factors are approximately 1.9. For these calculations, the compressive yield strength of the 7050 aluminum was taken as $60 \mathrm{ksi}$; ultimate strength used was $70 \mathrm{ksi}$.

${ }^{3}$ Factor of safety for yield is computed by:

$$
F S_{\text {yield }}=\frac{S_{\text {yield }}}{\sigma_{\mathrm{MPE}}}
$$

Factor of safety for ultimate is computed by:

$$
\begin{gathered}
\text { where } S_{\text {yield }}=\text { material yield strength } \\
S_{\text {ultimate }}=\text { material ultimate strength } \\
\sigma_{\mathrm{MPE}}=\text { stress calculated with Maximum Predicted } \\
\text { Environment (MPE) }
\end{gathered}
$$

$$
F S_{\text {ultimate }}=\frac{S_{\text {ultimate }}}{\sigma_{\mathrm{MPE}} * 1.25}
$$




\section{Test Design and Analysis}

Prior to performing the qualification tests of ESPA, considerable effort was expended into the identification of appropriate instrumentation, qualification loads, and the design of the reaction structure. While many decisions regarding these issues were based on results generated from the numerous structural analyses of the ESPA structure during design, the performance of ESPA during the qualification tests ultimately determines whether it is suitable for flight. As a result, extreme measures were taken to ensure that the test design, and subsequent experimental data generated during the qualification tests, accurately represented the design flight load and performance.

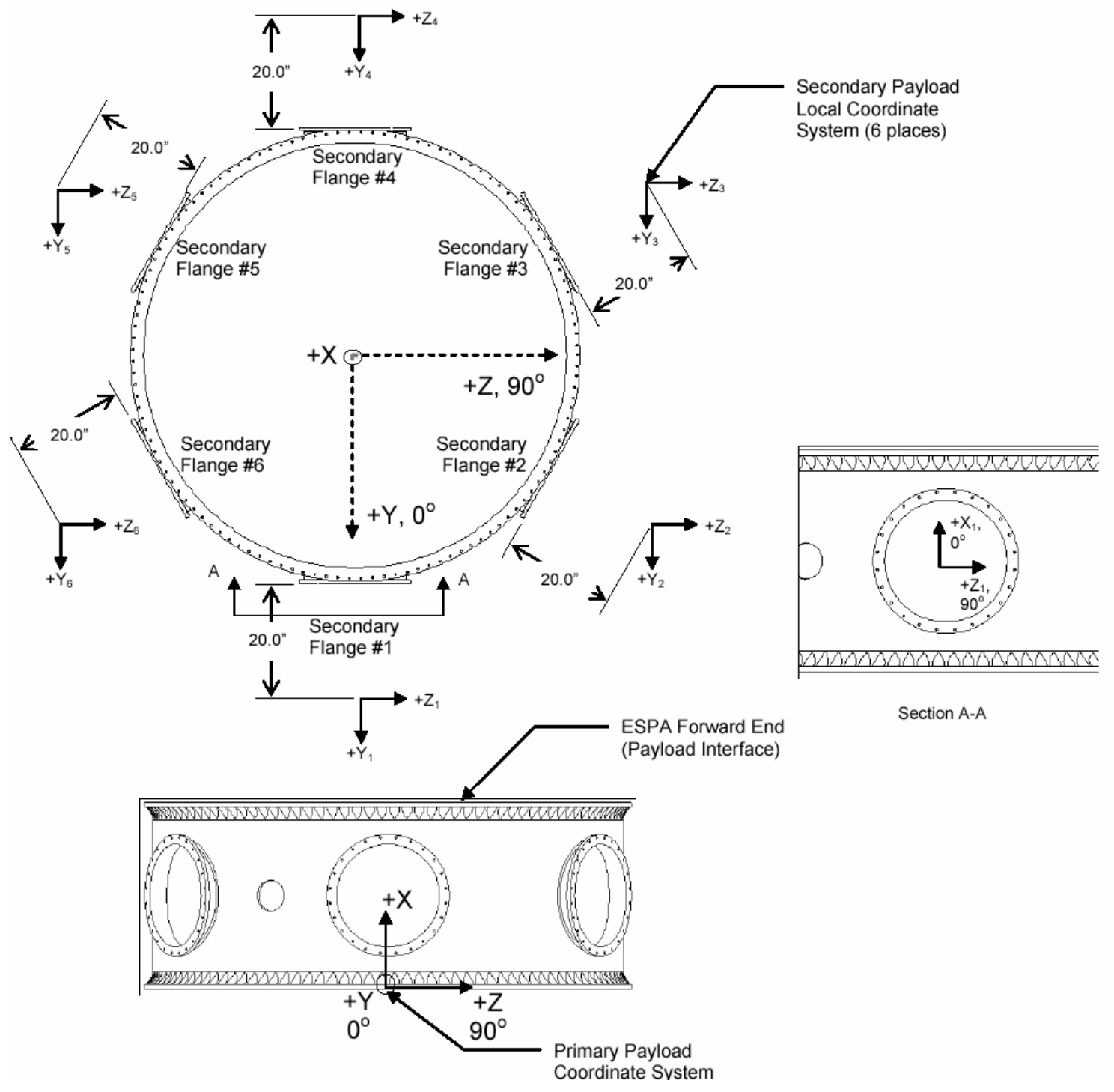

Figure 13. Qualification test coordinate systems 


\section{Shock Isolation Designs}

Whole-spacecraft isolation for ESPA payloads was considered seriously beginning in 1998, using preliminary finite element models of the ESPA with cantilevered secondary payloads. Specific designs were not targeted at the time, but because of the ESPA design focus (no added risk to the primary spacecraft due to the secondaries or the ESPA ring itself), launch stack dynamics had to be considered early in the design process.

Shock isolation for spacecraft mounted on ESPA have been designed, built, and tested, to protect spacecraft components, instruments and electronics during events such as staging events and fairing separation. ESPA-classspacecraft shock isolation systems are based on the SoftRide ShockRing design, a wholespacecraft isolation system that shock isolates the complete spacecraft from the launch vehicle. The ShockRing is targeted at shock loads and is set to isolate above approximately $75 \mathrm{~Hz}$. Component tests have been performed on the ShockRing using a specially built pneumatic gun that can generate 10,000 g's on the test article. Results from these tests demonstrate substantial reductions of the shock being transmitted to the payload. System testing consisting of a spacecraft simulator, payload attachment fittings, avionics section, and shock plate has also been performed. In the system tests, pyrotechnic devices were used to obtain the high levels of shock for the tests.

The ShockRing design for a whole-spacecraft shock isolation system is shown in Figure 14. The ShockRing is a continuous ring made of a series of highly damped flexures. The designed-in compliance, the high damping, the contorted shock path, and the joints all combine to make this an effective lightweight isolation system. This design and several others that are in development have been tested.

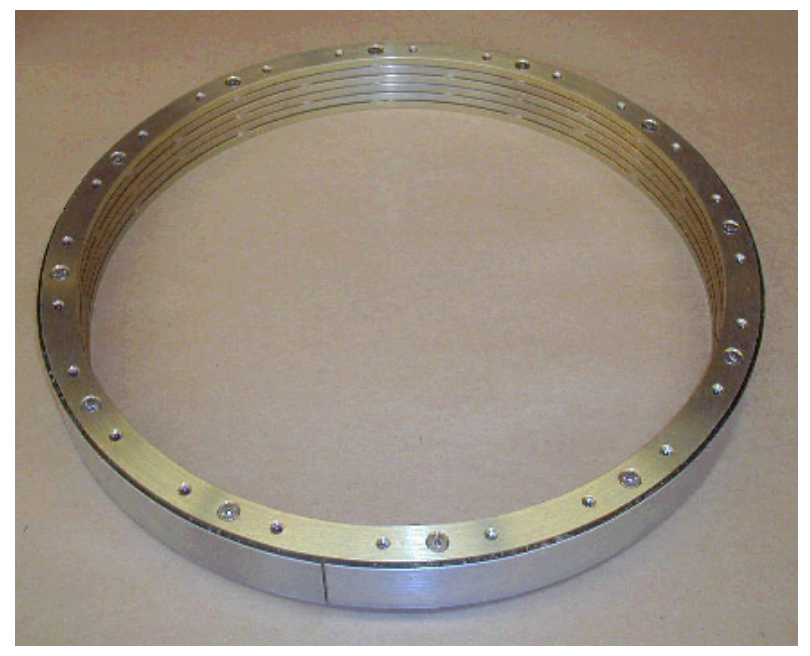

Figure 14. Patented whole-spacecraft shock isolation ring

Laboratory testing of shock isolation prototypes is performed using a pneumatic impact gun. The test setup is illustrated in Figure 15. The shock isolator is attached to two rigid steel blocks and suspended from a test frame. The pneumatic impact gun is a device that uses air pressure and a fast-acting pneumatic valve to impart a high velocity to a projectile that impacts the test article. The impact occurs on the steel block referred to as the "base" and the accelerations are measured on both the base and the "payload" steel block. Acceleration time histories and their corresponding shock response spectra for a typical test are shown in Figure 16. 

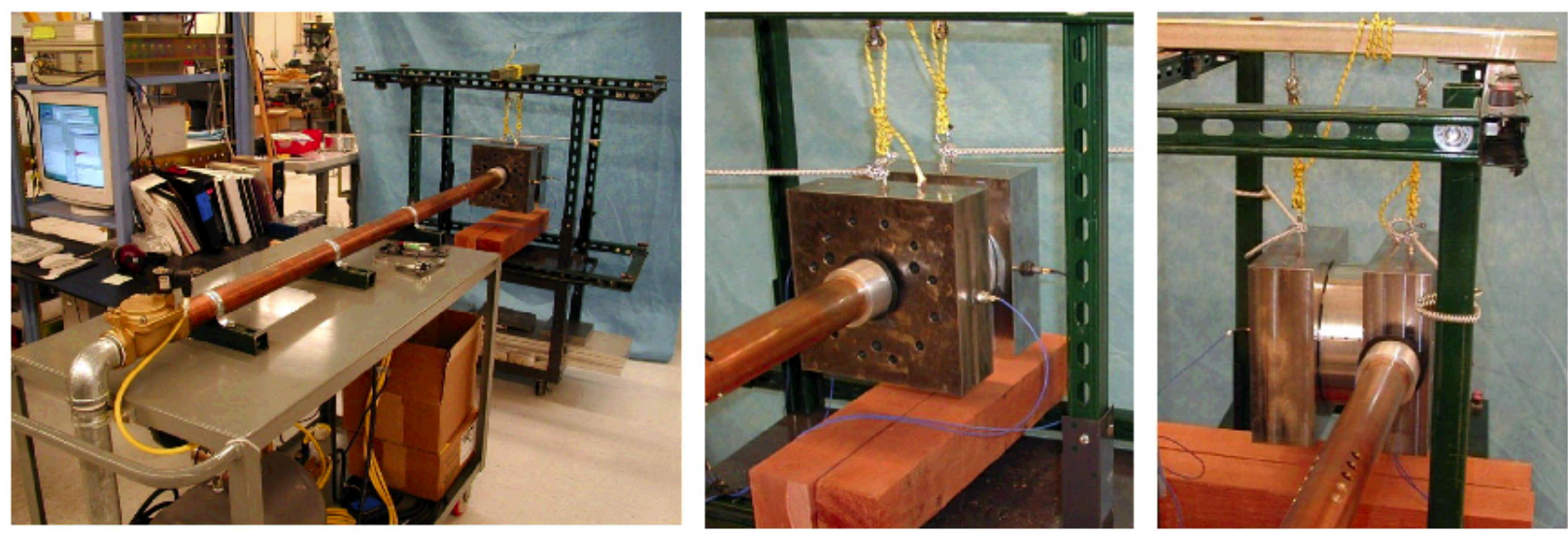

Figure 15. Test setup of pneumatic impact gun and ShockRing
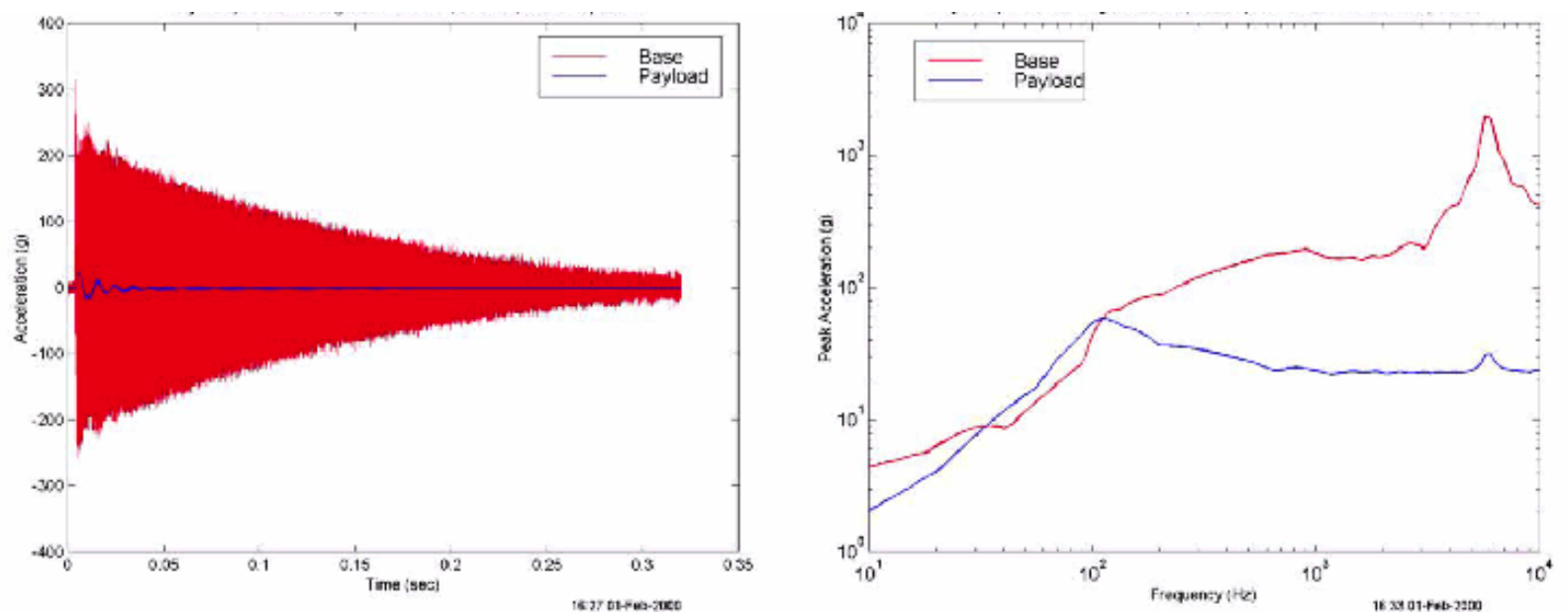

Figure 16. Time history data and shock response spectra from ShockRing impact gun testing

Pneumatic impact gun testing is very useful for development of shock isolation systems, but promising concepts have been taken to the next level with (1) flight-like pyrotechnic excitation and (2) flight-like flexible adjoining structures (as opposed to rigid blocks). Shock tests have been conducted using primacord for pyrotechnic excitation, launch vehicle components, and a spacecraft simulator. The amount of primacord was experimentally adjusted until targeted shock acceleration levels were measured at the spacecraft interface. Then, a ShockRing isolator was inserted into the stack, just aft of the spacecraft, and the tests were repeated. Accelerations were measured in all coordinate directions at several locations. Figure 17 shows acceleration time histories and shock response spectra from the test of a ShockRing. Data is shown for accelerometer locations both forward and aft of the isolator. The excellent attenuation performance of the shock isolator can be seen in both the time and frequency domains. 

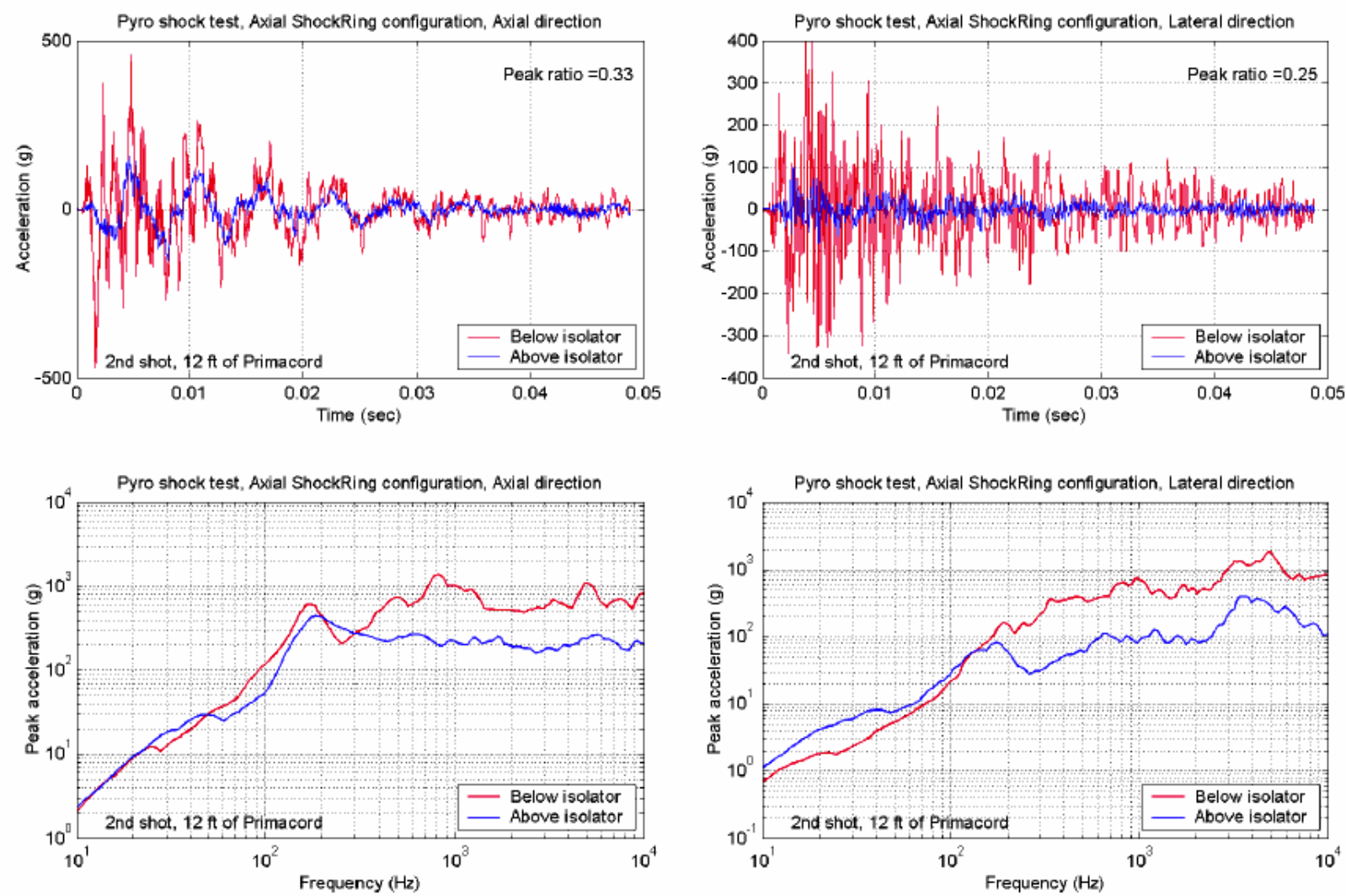

Figure 17. Time history data and shock response spectra from ShockRing pyrotechnic testing 


\section{STP-1, the Inaugural Mission}

Every four years, the Air Force Space Command (AFSPC) provides STP a medium class launch vehicle to support STP in flying the maximum possible Space Experiment Review Board (SERB) payloads. The next Air Force Delta IV mission is scheduled for March 2006. STP-1, expected to be the maiden voyage for ESPA, has been in development since July 2001. This first flight will be heavily instrumented so that a full flight validation can be done post-flight.

Figure 18 shows a solid model of the STP-1 launch stack. The spacecraft that have been manifested for STP-1 include:

- Orbital Express, a DARPA spacecraft being developed by a Boeing-led team,

- STPSat1, an STP spacecraft under development by AeroAstro,

- NPSat1, from the Naval PostGraduate School in Monterey California,

- FalconSat3, from the US Air Force Academy, and

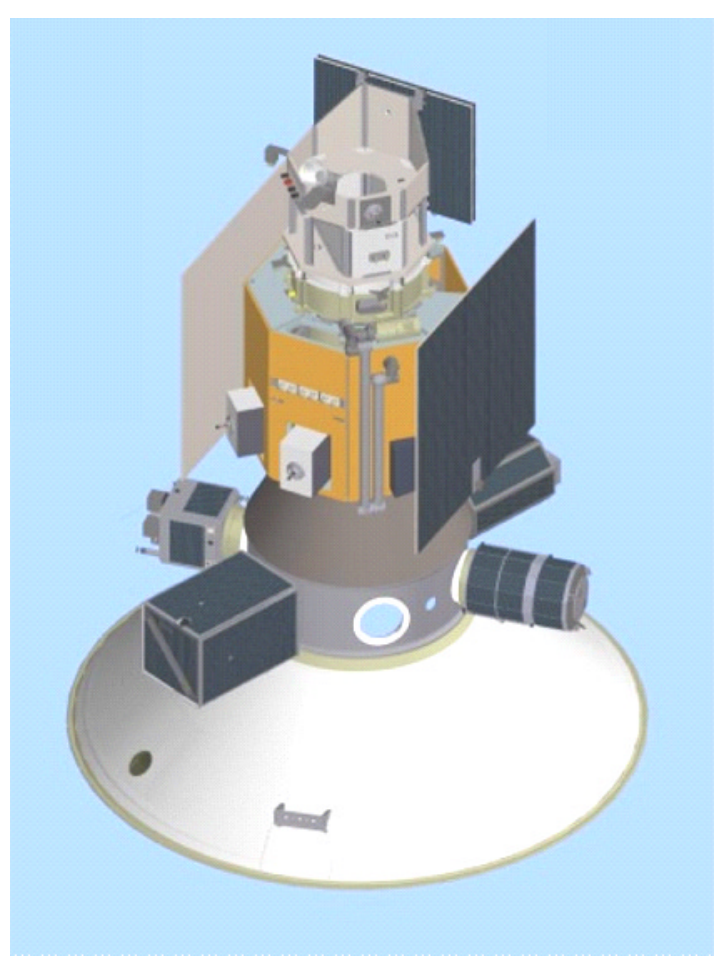

Figure 18. STP-1 spacecraft on ESPA, courtesy The Boeing Company

- MidStar1, from the US Naval Academy.

\section{Conclusion}

The Air Force Space Test Program (STP), part of the Space and Missile Systems Center Detachment 12, identified large unused payload margins on the majority of DOD's EELV manifests. In some cases this unused lifting capacity approached $8000 \mathrm{lb}$. So STP advocated using this excess margin for the deployment of secondary payloads, and assembled a development team led by the Air Force Research Laboratory, Space Vehicles Directorate. The result was ESPA.

Specifications for ESPA spacecraft are provided in the ESPA User's Guide available from STP. It is now feasible for up to six secondary spacecraft to be placed in orbit whenever an EELV launch with the 62.01-inch interface is configured with excess payload capacity. Since the majority of EELV launches in the foreseeable future have significant excess capacity, the small satellite community has a significant new option for access to space. 


\section{Acknowledgments}

Development of the Evolved Expendable Launch Vehicle Secondary Payload Adapter was an enormous effort, and numerous individuals from many organizations contributed. We regret if anyone's name was not included here that should be.

The authors wish to thank Major Scott Haskett, USAF, Steve Buckley, Northrop Grumman Corp., Les Doggrell, Aerospace Corp., Lt Colonel Dave Tobin, USAF, Major Bruce Wilder, USAF, Major Gary Haag, USAF, and Lt Colonel Gary Hendel, USAF, for contributions to this paper, especially the historical details of the ESPA Program.

Many contributed to the development of ESPA, including, but not limited to, those listed above and the following: Gene Fosness, AFRL, Dino Sciulli, AFRL, Steve Huybrechts, AFRL, Steve Weis, Aerospace Corporation, Conor Johnson, CSA Engineering, Michael Evert, CSA Engineering, Jeff Welsh, AFRL, Barry Berenberg, AFRL, Jeff Ganley, AFRL, Troy Meink, AFRL, Waylon Gammill, AFRL, Karl Jurisson, Northrop Grumman, Joe Delgado, Northrop Grumman, Dave Kendall, Northrop Grumman, Lex Granda, Northrop Grumman, Elise Kovacic, Northrop Grumman, Ed Zabrensky, Northrop Grumman, Col James Neumeister, USAF, Major Mark Mocio, USAF, Major Paul Hesse, USAF, Lt Jeffrey Zdenek, USAF, Lt Hans Carlson, USAF, Lt Jeremy Goodwin, USAF, Lt Ross Keener, USAF, Lt Rick Caldwell, USAF, Nick Martino, Aerospace Corporation, Bob Peach, Aerospace Corporation, Jim Goodding, AFRL/CSA Engineering, Emily Fowler, CSA Engineering, Raman Johal, CSA Engineering, Jason Salmanoff, CSA Engineering, Scott Pendleton, CSA Engineering, Ken Telford, Boeing, Peter Hatch, Boeing, Art Hemphill, Boeing, Don Edberg, Boeing, Henry Fan, Boeing, Mike Tracy, Boeing, Walter Tsui, Boeing, Robert Boucher, Boeing, John Musarra, Scitor Corp, Bob DiTolla, Lockheed Martin, John Bradford, Lockheed Martin, Eric Johnson, Lockheed Martin, Larry Snodgrass, Lockheed Martin, Rob Scarborough, Lockheed Martin.

\section{$\underline{\text { References }}$}

Haskett, Capt. S.A., L.J. Doggrell, E.R. Fosness, D. Sciulli, T.E. Meink, and J.R. Maly, "EELV Secondary Payload Adapter (ESPA)," Proceedings of $13^{\text {th }}$ Annual AIAA/USU Conference on Small Satellites, Logan, Utah, August, 1999.

Kendall, R., ed., "Evolved Expendable Launch Vehicle, Standard Interface Specification, Version 6.0," Evolved Expendable Launch Vehicle Program Office and Aerospace Corporation, September, 2000.

Goodwin, Lt J.S. and P.M. Wegner, "Evolved Expendable Launch Vehicle Secondary Payload Adapter-A New Delivery System for Small Satellites," Proceedings of $15^{\text {th }}$ Annual AIAA/USU Conference on Small Satellites, Logan, Utah, August, 2001.

Higgins, J.E., B.J. Arritt, E.R. Fosness, P.M. Wegner, and S.J. Buckley, "Multiple Payload Adapters; Opening the Doors to Space," Proceedings of $16^{\text {th }}$ Annual AIAA/USU Conference on Small Satellites, Logan, Utah, August, 2002.

Sanford, G.E., "Development and Structural Qualification of the EELV Secondary Payload Adapter (ESPA)," Proceedings of $43^{\text {rd }}$ AIAA/ ASME Structures, Structural Dynamics, and Materials Conference, Denver, Colorado, April, 2002.

Maly, J.R., P.S. Wilke, E.C. Fowler, Capt S.A. Haskett, D. Sciulli, and T.E. Meink, "ESPA: EELV Secondary Payload Adapter with WholeSpacecraft Isolation for Primary and Secondary Payloads," Proceedings of SPIE $7^{\text {th }}$ Annual International Symposium on Smart Structures and Materials, Newport Beach, California, March 2000 .

Johnson, C.D. and P.S. Wilke, "Whole-space-craft shock isolation system," Proceedings of SPIE $9^{\text {th }}$ Annual International Symposium on Smart Structures and Materials, San Diego, California, March 2002. 